\title{
FUTEBOL-PAIXÃO: O que marca?
}

\author{
Tatielle Haussen Reis \\ UNIVATES \\ tatimsv@hotmail.com \\ Elizete de Azevedo Kreutz \\ UNIVATES \\ eakreutz@univates.br
}

\begin{abstract}
Resumo: Marca é uma representação simbólica, cuja função é não somente identificar um produto/serviço, como também produzir sentido aos seus públicos, a partir das características qualitativas que os estimulam sensivelmente. Porém, devido à falta de comunicação estratégica das empresas, isso nem sempre acontece, o que ocasiona a não valorização dessas marcas. A paixão do público por uma marca varia de acordo com os vínculos emocionais estabelecidos com esta. Isso pode ser percebido com nitidez nas marcas de times de futebol, posto que estas são populares e o público não tem vergonha de expor os sentimentos por elas. Buscando entender os fatores que interferem na construção e consolidação de uma marca emocional, neste trabalho, foi realizada uma análise dos times de futebol, os quais fazem parte da formação inicial do Clube dos Treze, focando nos times do Rio Grande do Sul, Grêmio Foot-Ball Porto Alegrense e Sport Club Internacional. Para isso, foi utilizada como metodologia a Hermenêutica de Profundidade de Thompson (1995), apoiada pelas técnicas de pesquisa: revisão bibliográfica (AZEVEDO E SOUZA, 1995), entrevista (GASKELL, 2002), análise de conteúdo (BAUER, 2002) e semiótica (PENN, 2002). Com os resultados obtidos, espera-se apresentar o processo de construção e consolidação das marcas de times de futebol e a capacidade de interação e identificação com o torcedor, para que as estratégias apresentadas, posteriormente, possam servir de referência para as demais marcas.
\end{abstract}

Palavras-chave: Marca; Design Emocional; Estratégias; Times de futebol.
Abstract: Brand is a symbolic representation, whose function is not only to identify a product/service, but also produce sense to publics from their qualitative characteristics that stimulate feelingly. But, due to lack of strategic communication of corporates, it doesn't happen, which results in not appreciation of such brands. The public passion for a brand changes according with emotional link create by it. This can be seen clearly in brands of soccer teams, considering that those are populars and the 
public is not ashame to expose feeling for them. Seeking to understand the factors that interfere in the construction and consolidate of an emotional brand, in this work was performed analysis of the soccer teams that are part of the initial formation of the Clube dos Treze, focusing in Rio Grande do Sul teams, Grêmio Foot-Ball Porto Alegrense and Sport Club Internacional. For this, was used as methodology the Depth Hermeneutics of Thompson (1995), supported by the research techniques: bibliographic review (AZEVEDO E SOUZA, 1995), interview (GASKELL, 2002), content analysis (BAUER, 2002) and semiotics (PENN, 2002). With the results, expected to show the process of construction and consolidation of the soccer team's brands and the ability to interact and identify with the fan, so that these strategies presentations, later, can serve as a reference for other brands.

Keywords: Brand; Emotional Design; Strategies; Soccer teams.

\section{INTRODUÇÃO}

A construção de uma marca não é só a concepção de uma identidade visual corporativa que representa um produto/serviço ou ainda uma organização, por meio de características específicas, permitindo a sua identificação pela sociedade e diferenciando-a de seus concorrentes. Como formas simbólicas, as marcas são mais do que isso, pois buscam fazer sentido para os públicos, com o intuito de estabelecer uma relação de afeto entre elas e os mesmos, fazendo com que, mais do que identificar e reconhecer, estes se identifiquem com tais marcas e atribuam um valor superior a elas. Dessa forma, as marcas também passam a fazer parte da construção da sociedade, do seu imaginário coletivo, estando presentes no dia-dia de seus fiéis consumidores e tornando-se, muitas vezes, uma paixão.

Essa paixão dos públicos por uma marca varia de intensidade de acordo com os vínculos emocionais estabelecidos. Isso pode ser percebido com mais nitidez nas marcas de times de futebol, posto que estas são populares e o público não tem vergonha de expor os sentimentos por elas. Observa-se também que isso acontece com algumas marcas, como a Coca-Cola e a Harley Davidson.

Buscando entender os fatores que interferem na construção e consolidação das marcas de times de futebol, enquanto marcas emocionais, e a capacidade de interação e identificação com o torcedor, deu-se início a este estudo, cujo tema principal é o futebol e seus símbolos como constituintes de marca. Durante o seu desenvolvimento foram feitas análises e pesquisas no sentido de elucidar questões relacionadas à temática, buscando compreender como determinados elementos visuais, bem como, determinadas combinações destes (símbolos), provocam estímulos específicos aos públicos, para que sirvam de referência às demais marcas. Para isso, os estudos foram direcionados aos times pertencentes à formação inicial do Clube dos Treze, com foco nas duas principais agremiações do Rio Grande do Sul, Grêmio Foot-Ball Porto Alegrense e Sport Club Internacional.

A metodologia utilizada foi a Hermenêutica da Profundidade de Thompson (1995). Nessa estrutura, destaca-se a proposta da Tríplice Análise que abrange os seguintes campos: análise sócio histórica, análise formal-discursiva e interpretação e reinterpretação. Buscando contextualizar e compreender melhor as características do 
objeto de estudo - marcas de times de futebol e torcedor - foi realizada uma análise do seu contexto histórico e local e de seus símbolos e representações na sociedade, utilizando como base a pesquisa bibliográfica (AZEVEDO E SOUZA, 1995), semiótica (PENN, 2002), entrevistas (GASKELL, 2002) e análise de conteúdo (BAUER, 2002).

As entrevistas semiestruturadas foram realizadas individualmente a membros de um grupo específico, no total de 12 pessoas, sendo seis torcedores gremistas e seis torcedores colorados, que variavam entre torcedores fanáticos e não fanáticos. $\mathrm{Na}$ primeira fase das entrevistas, selecionou-se os sujeitos a partir de sua afinidade com os times escolhidos, Grêmio e Internacional ${ }^{1}$, e seus conhecimentos sobre os mesmos, ao responderem algumas perguntas exploratórias. Em seguida, foram aplicadas questões relacionadas com estímulos associados às marcas dos times estudados, sendo utilizados escudos, cores e cantos para a captação da reação do torcedor com o que Ihe foi proposto. Na última etapa, foram analisadas, de acordo com análise de conteúdo proposta por Bauer (2002), as principais respostas tanto racionais quanto emocionais dos entrevistados, em relação às perguntas específicas dos elementos, as quais serão indicadas no decorrer do trabalho.

Por fim, seguindo o sentido da Tríplice Análise de Thompson (1995), na etapa de interpretação e reinterpretação, analisou-se todos os dados e conhecimentos obtidos durante o trabalho, possibilitando a visualização e o entendimento dos resultados de forma clara e coerente. Posteriormente, com base nos resultados, foram destacados elementos e tópicos utilizados pelas marcas de times de futebol e reconhecidos pelos torcedores, que podem ser empregados em marcas no geral, projetando melhorias à área específica.

\section{Marca, futebol e paixão: uma breve descrição.}

O consumidor é a pessoa que tem por hábito consumir, comprar determinados produtos ou serviços para satisfazer suas necessidades básicas e/ou desejos, tentando satisfazer além do que o organismo necessita (STOLZ, 2000). Cada grupo específico da população consome conforme as influências que recebe do meio em que se encontra inserido. Dessa forma, tendo por base a concepção de diversos autores, o consumo pode estar vinculado com o contexto sócio histórico do qual o indivíduo faz parte, podendo ser interferido pela cultura, faixa etária, instituições formadoras e classe social, ainda, ele pode estar relacionado com as características do produto, envolvendo sua marca, qualidade, representação visual e demais atributos.

O hábito e a maneira de consumo, portanto, encontram-se impostos pelo ambiente e pelos grupos de convívio com os quais cada indivíduo interage e se identifica, definindo seus gostos e preferências. Para isso, existem marcas que sustentam produtos e serviços desenvolvidos especialmente para esses públicos, sendo levado em consideração a possibilidade de interação e identificação do indivíduo com o que lhe é oferecido. Em consequência, existem marcas que se tornam referência estabelecendo uma forte relação de afeto com o consumidor e, em alguns casos, transformando-se em uma paixão.

Se antes se priorizava a ideia de produtos e consumidores, na contemporaneidade, pensa-se em marcas e seus públicos. Independente de ser uma

\footnotetext{
${ }^{1}$ O Sport Club Internacional será tratado como Internacional, ou ainda somente como Inter, enquanto o Grêmio Foot-Ball Porto Alegrense será chamado de Grêmio, como são conhecidos no Rio Grande do Sul e no Brasil.
} 
marca, um serviço, um produto, uma pessoa ou mesmo um time de futebol, e os públicos serem ou não consumidores, considera-se aqueles que de alguma forma estão envolvidos ou são de interesse da marca e que lhe atribuem valor significativo. Um exemplo de marcas de valor, que provocam emoção aos seus públicos são as de times de futebol, que interagem de forma intrínseca com seus torcedores.

De acordo com a história do futebol, desde seu surgimento, o esporte se tornou parte da formação da cultura brasileira, estando presente na concepção de identidade do país. Como afirma Jocimar Daolio (2005), o futebol se torna não só uma forma de representação do Brasil, como também do homem brasileiro. Este passa a se identificar com ele por meio da relação existente entre suas vivências e os acontecimentos do ambiente do futebol, sendo elas as emoções, os desejos, os aprendizados, entre outros fatores que cooperam para isso. Assim, o futebol que na visão geral pode ser encarado somente como o esporte que envolve dois times compostos por 11 jogadores cada, cujo objetivo final é fazer gols em busca da vitória, pode ser compreendido também como um conjunto simbólico formado por seus signos, títulos, emblemas e demais elementos que compõem e criam essa estrutura representativa para a sociedade brasileira, independente da faixa etária, classe social ou descendência.

O fato é que o povo se une, nem que somente por 90 minutos, para ver o seu time em campo, para torcer junto, esperando um gol, a vitória, que muitas vezes nem chega e vira lágrimas, em alguns casos, desespero. O futebol acaba por provocar a emoção de seus fiéis torcedores, fazendo-os agir por instinto, dando origem aos seus rituais, aos cantos de guerra e aos outros envolvimentos que cooperaram e ainda auxiliam na concretização da marca do seu time de futebol.

A marca de seu time específico, muitas vezes, serve de referência para o convívio dos torcedores, fazendo parte da sua identidade e caracterização dentro da sociedade, o torcedor passa a ser incluído em um grupo com o qual se assemelha e troca informações, se sentindo cada vez mais motivado para o consumo de tal marca. Por consequência, ele encontra-se introduzido em um mundo de emoções, em que seus sentimentos surgem de maneira espontânea, sem o controle da razão, pelo simples fato de exposição com os elementos que compõem a marca de seu time (símbolos, cores, momentos, vitórias, derrotas, cantos de guerra, etc.), tudo isso indica nitidamente a imensa paixão e fidelidade que o torcedor sente em relação ao seu time de afeto e que não tem vergonha de demonstrar (FIGURA 1).

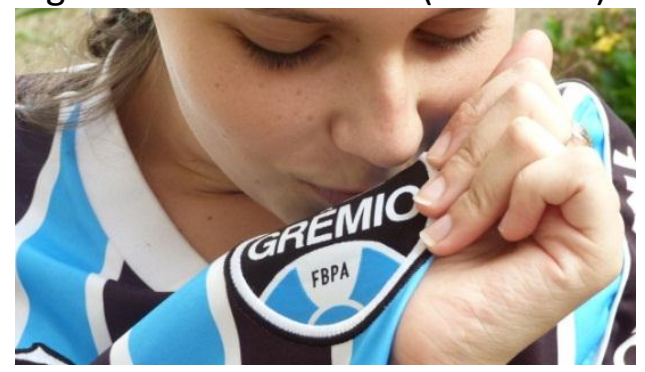

Figura 1 - Torcedor gremista beijando o escudo do time.

Fonte: Elaborado pelo autor, com base na pesquisa realizada.

Falar de emoção não é uma tarefa muito fácil, todos têm a capacidade de compreendê-la, uma vez que ela faz parte da estruturação da mente, porém, é difícil defini-la ou explicá-la precisamente. A emoção está diretamente ligada com os gostos e prazeres, medo, angústias, alegrias, surpresas, provocando todos os sentimentos. De 
acordo com diversos autores estudados, sua essência pode surgir instintivamente por meio de acontecimentos inesperados e surtir efeitos de espontaneidade, não podendo ser controlada, já que esta se encontra no inconsciente, ao contrário da razão, que é processada pelo consciente e pode ser mais facilmente dominada.

Segundo LeDoux (2001), o ser humano toma a maioria de suas decisões seguido pelo seu lado emocional. A emoção predomina a escolha de cada ato que este exerce, sendo tão importante quanto a razão para a construção de uma vida saudável. De acordo com o autor, a mente não existe sem emoção, ele afirma que o hemisfério direito do cérebro exerce uma ação racional que é explicada por um movimento inconsciente proposto pelo hemisfério esquerdo, que acontece por meio das lembranças passadas que estão pré-concebidas na mente do ser humano para serem utilizadas em ocasiões específicas.

Sob essa perspectiva, compreende-se que a tomada de decisão é derivada em grande parte da mente inconsciente, afinal, o cérebro funciona na maioria das vezes no piloto automático, e a mente consciente tem pouco acesso direto ao sistema neural (EAGLEMAN, 2012). As decisões, dessa forma, provêm de uma série de conceitos, ideias e conhecimentos pré-estabelecidos que constituem o imaginário dos públicos, formado pelas imagens captadas e armazenadas ao longo do tempo pela mente, que induzem a escolha por determinados produtos e/ou marcas de uma forma instintiva.

Existem diferentes elementos que fazem parte da construção de uma marca e que fazem com que essa seja reconhecida pelos públicos, constituindo seu imaginário. Dentre esses elementos, que caracterizam e agregam valor à marca, destacam-se, os símbolos, as mascotes, as cores, os jingles, as experiências e a identidade visual.

Para compreender os símbolos presentes no ambiente do futebol associados à estruturação das marcas de times e o cenário construído no imaginário dos torcedores, realizou-se a análise semiótica dos mesmos. No primeiro momento, foram analisadas as cores, seguidas pelos símbolos e mascotes, que juntos representam as características de cada time, com as quais o torcedor se identifica como marca.

\subsubsection{Cores}

Segundo Guimarães (2001), a cor abrange todos os componentes (o objeto, a luz, o órgão da visão, o cérebro) do imaginário. Assim, ela pode ser compreendida como um elemento que transmite uma informação aos olhos de seu espectador, a qual é interpretada conforme seus conhecimentos pré-concebidos a respeito desta.

Durante o trabalho as cores foram analisadas em conjunto e inseridas dentro do contexto relacionado com seus times, Grêmio e Internacional (QUADRO 1). As marcas de times de futebol são identificadas conforme o uso de cores específicas e as características que estas agregam às mesmas. As cores são elementos constituintes da marca, por isso, são essenciais na sua caracterização. Uma representação visual, por exemplo, não transmitiria o mesmo sentido se fosse sem cores, portanto, não causaria o mesmo impacto sensorial ao ser percebida. A combinação dessas cores também pode se tornar característica da marca, uma vez que esse conceito é concebido pela sociedade como forma de identificação e distinção.

Quadro 1 - Combinações das cores do Grêmio e do Internacional

\begin{tabular}{|c|c|}
\hline Azul + Branco + Preto & Vermelho + Branco \\
\hline & \\
\hline
\end{tabular}

Fonte: Elaborado pelo autor, com base na pesquisa realizada. 
Dessa forma, a união das cores azul, branco e preto, especialmente dentro do contexto do futebol do Rio Grande do Sul, remete ao time do Grêmio. Essa combinação de cores concedeu ao time a titulação de tricolor gaúcho, característica que se tornou parte de sua identidade. Também devido às suas cores, os torcedores do Grêmio dizem que possuem a alma tricolor ou azul celeste, como afirma o canto da Geral $^{2}$ : "Eu sou o tricolor de Porto Alegre. Eu tenho a minha alma azul celeste...".

Da mesma forma que acontece com as cores representativas do Grêmio, dentro do contexto apontado, ocorre com a união do vermelho e do branco que evoca a lembrança do Internacional. Devido a essas cores, especialmente o vermelho, o time e seus torcedores são chamados de colorados, existem canções referentes a essa característica, como: "É COLORADA a cor do meu sentimento...". Um dos fatos marcantes em sua história, foi quando o time se tornou Campeão do Mundo, motivando uma campanha que contrariava a ideia de que a Terra é azul, sendo representada pelos seus torcedores pela cor vermelha.

Outro ponto referente às cores, azul e vermelho, que implica na caracterização do Grêmio e do Inter, é a combinação delas. Quando unidas, pode-se dizer que surge a representação de um Grenal $^{3}$, que tornou-se elemento essencial para a concretização desses dois times, devido a competitividade exigida pelo futebol que implica na meta de tentar vencer os adversários, uma vez que a marca de um time não existiria se não houvesse o outro para confrontar.

\subsubsection{Escudos}

O distintivo do Grêmio foi criado em 1903, no mesmo ano de sua fundação, e sua imagem representava a primeira bola do clube. O escudo era composto por gomos nas cores azul, branca e preta que eram associados à figura da bola (FIGURA 2 A). 0 símbolo do Grêmio não teve muitas alterações, permanecendo muito semelhante à sua concepção original. Somente em 1963, o clube fez algumas mudanças no seu distintivo, alterando traços de representação da bola e as inscrições contidas no escudo (FIGURA 2 B). Mais tarde, devido às conquistas obtidas pelo time foram anexadas ao seu escudo algumas estrelas que simbolizavam suas vitórias. Cada estrela representava um título: a estrela de bronze referente ao Campeonato Brasileiro de 1981, a estrela de prata à Copa Libertadores da América de 1983 e a estrela de ouro ao Campeonato Mundial de Interclubes de 1983 (FIGURA 2 C) (GRÊMIO FOOT-BALL PORTO ALEGRENSE, 2010).
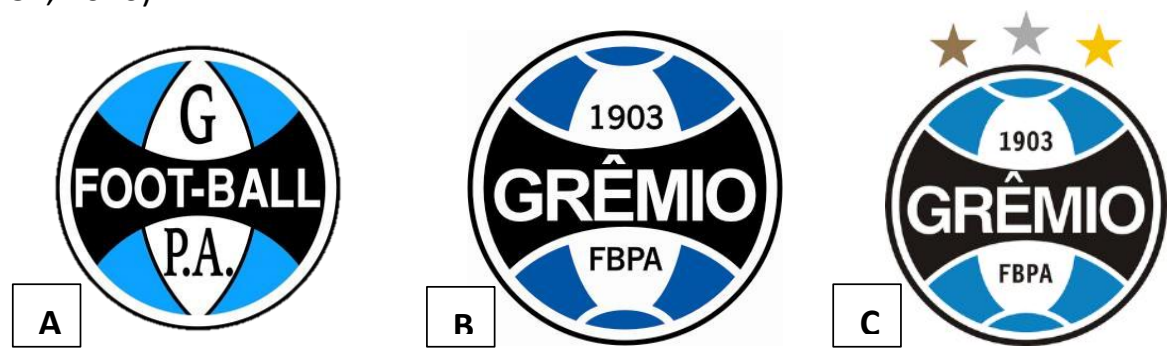

FIGURA 2 - A) Primeiro escudo do Grêmio Foot-Ball Porto Alegrense; B) Escudo do

Grêmio modificado em 1963; C) Escudo do Grêmio com estrelas referentes às grandes conquistas.

Fonte: A) Sempre Imortal (2010);B) Analises Dom Joker (2010);C) Rafael Nemitz (2010).

\footnotetext{
${ }^{2}$ Atual maior torcida do Grêmio, criada em 2001 (BLOG ORGANIZADAS, 2010).

${ }^{3}$ Clássico do futebol brasileiro em que o Grêmio e o Internacional se enfrentam.
} 
Assim como o do Grêmio, o escudo do time do Internacional não sofreu grandes alterações ao longo de sua evolução. Desde sua criação ele é representado pelas iniciais $\mathrm{SCl}$ (Sport Club Internacional) e pelas cores vermelha e branca, mantendo a essência de formação do símbolo (FIGURA 3 A). Durante a trajetória do clube foram modificados apenas alguns traços das iniciais e do círculo que as abriga. Ainda, conforme suas conquistas foram adicionadas ao distintivo as estrelas respectivas aos grandes desafios vencidos pelo time e modificadas algumas de suas características em escudos comemorativos (FIGURA $3 \mathrm{~B}$ ). Atualmente, o escudo do Internacional, desenvolvido para o centenário, é composto pelas iniciais $\mathrm{SCl}$ sobre o círculo vermelho que possuí uma espessa borda branca com a seguinte inscrição: S.C. INTERNACIONAL, além do ano de sua origem - 1909 (FIGURA 3 C) (SPORT CLUB INTERNACIONAL, 2010).
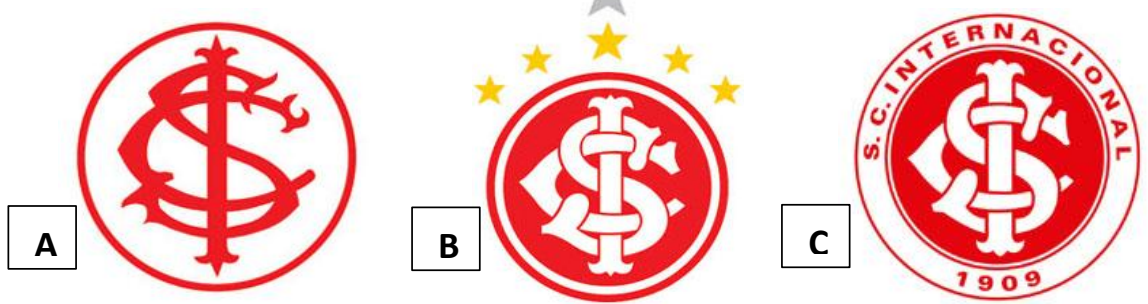

FIGURA 3 - A) Primeiro escudo do Internacional; B) Escudo do Internacional depois da conquista do Mundial (2006); C) Escudo do centenário do Internacional. Fonte: Sport Club Internacional (2010).

\subsubsection{Mascotes}

A mascote oficial do Grêmio é o mosqueteiro (FIGURA 4 A). Ele foi criado em 1946 pelo chargista Pompeo do jornal Folha da Tarde/Correio do Povo e inspirado na mascote do Corinthians, que já fazia o uso do mosqueteiro desde 1919. No mesmo ano, o mosqueteiro já era reconhecido pela torcida, estando incluso em faixas expostas pelas mesmas junto com a inscrição: "Com o Grêmio, onde estiver o Grêmio", frase que posteriormente foi modificada para fazer parte do hino oficial do time. Durante sua história, a mascote do Grêmio (FIGURA 4 B) sofreu algumas modificações em sua composição, mas nunca teve seu conceito inicial alterado.
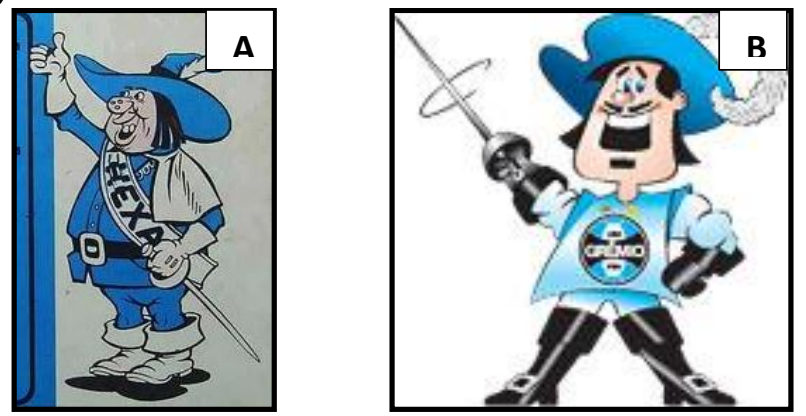

Figura 4 - A) Concepção antiga do mosqueteiro representante do Grêmio; B) Imagem atual do mosqueteiro, mascote do Grêmio.

Fonte: Grêmio 1983 (2010).

Na década de 1950 o Internacional utilizava a imagem de um negrinho como sua mascote, este com sua representação irônica e malandra permitia a identificação do time como um clube do povo que aceitava associados de diferentes raças e classes sociais. Depois, a mascote do Internacional passou a ser o saci (personagem que gosta de armar ciladas) em homenagem às táticas armadas pelo time contra seus 
adversários. Assim, o Inter permaneceu com a figura de um menino negro que o identificava como um clube do povo, acrescentando ainda a imagem de um personagem já conhecido no folclore brasileiro com o qual possuía características afins (FIGURA 5).

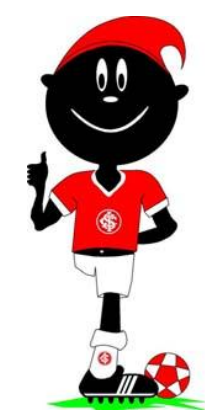

Figura 5 - Saci: Mascote do Internacional

Fonte: Sport Club Internacional (2010).

Os símbolos, bem como os demais elementos constituintes da marca do time são fundamentais para sua construção e concretização no ambiente do futebol. Cada um desses artefatos provoca no torcedor algum sentimento, que o envolve emocionalmente, permitindo que o mesmo interaja diretamente com a marca, o que pode ser percebido durante as entrevistas explanadas a seguir.

Tendo por base as características de constituição do imaginário coletivo e a importância dos aspectos emocionais para o envolvimento com a marca, foram realizados estudos direcionados especificamente ao torcedor, analisando suas reações racionais e emocionais em relação aos elementos que compõem a marca do seu time de afeto e dos times rivais.

A estruturação das entrevistas, conforme já indicado, foi feita embasada em modelos propostos por Gaskell (2002) e também a partir do conhecimento sobre o emocional obtido durante os estudos. Isso possibilitou a formação de um questionário que busca entender o que os torcedores de fato sentem em relação aos estímulos específicos de seu time e do rival. Com base nas entrevistas realizadas, foi possível diagnosticar algumas características importantes relacionadas com os torcedores e as marcas de times de futebol, principalmente, tratando-se de estímulos emocionais a elas associados.

O torcedor consegue se envolver diretamente com seu time, ele se identifica com cada elemento constituinte dessa marca. O hino, os cantos, o escudo, a mascote, tudo provoca nele uma emoção, o torcedor interage com cada minúcia do seu time se sentindo freneticamente estimulado. Como ele mesmo afirma nas entrevistas, o sentimento pelo seu time é algo incontrolável, o entusiasmo, a vibração, é tudo instintivo. $O$ torcedor não consegue controlar a sensação provocada pelos estímulos tanto do seu time quanto do time rival (TABELA 1). Normalmente, ele se sente instigado pelo que presencia sendo capaz de afirmar que o sentimento é repentino, que não pode ser bloqueado mesmo que aparentemente esteja visível, o que é controlado nesse caso é a vontade momentânea de expressar o que sente. 
Tabela 1. Controle da sensação provocada pelos estímulos.

\begin{tabular}{lccc}
\hline & Não Controla & Controla parcialmente & Controla totalmente \\
\hline Do seu time & $83,33 \%$ & $8,33 \%$ & $8,33 \%$ \\
\hline Do time rival & $58,33 \%$ & $25 \%$ & $16,66 \%$ \\
\hline
\end{tabular}

Fonte: Elaborado pelo autor, com base na pesquisa realizada.

Ao contrário do que sente pelo seu time, o torcedor afirma abertamente que sente repulsa, nojo, angústia, raiva e outros sentimentos citados durante as entrevistas em relação ao time rival. O torcedor sustenta uma rivalidade, uma provocação para com o outro time que é fundamental para ele, pois este adora assistir aos jogos do adversário para "secar", é quase pior o time rival ganhar um jogo do que seu próprio time perder. Essa concepção de rivalidade também já está tão concretizada na mente do torcedor que virou uma espécie de fanatismo, ele parece não conseguir ficar sem provocar o adversário. Isso pôde ser percebido com clareza nas entrevistas, na maioria dos casos, os torcedores falam mal do time adversário e não conseguem controlar o impulso provocado pelos estímulos. Ainda, em relação às experiências com o time adversário não foi relatado nenhuma vivência agradável ou que remetesse a uma boa lembrança (TABELA 2).

Tabela 2. Associação com experiências relacionadas com os times de futebol.

\begin{tabular}{lccc}
\hline & $\begin{array}{c}\text { Experiências } \\
\text { agradáveis }\end{array}$ & $\begin{array}{c}\text { Experiências } \\
\text { desagradáveis }\end{array}$ & $\begin{array}{c}\text { Não associa com } \\
\text { experiências }\end{array}$ \\
\hline Do seu time & $91,66 \%$ & $8,33 \%$ & 0 \\
\hline Do time rival & 0 & $75 \%$ & $25 \%$ \\
\hline
\end{tabular}

Fonte: Elaborado pelo autor, com base na pesquisa realizada.

Apesar de o torcedor demonstrar toda essa rivalidade para com o time adversário, conforme é apontado nas entrevistas, esse time não possui nenhum significado relevante para eles, com exceção de alguns torcedores que dizem ter um significado negativo. Já em relação a seu time de coração, os torcedores afirmam que sem dúvida o time é importante para eles, assegurando que este faz parte da sua vida e que o sentimento por ele é inexplicável (TABELA 3).

Tabela 3. Significado de cada time em relação aos estímulos.

\begin{tabular}{lcccc}
\hline & $\begin{array}{c}\text { Significado } \\
\text { importante }\end{array}$ & $\begin{array}{c}\text { Pouco } \\
\text { significado }\end{array}$ & $\begin{array}{c}\text { Não possui } \\
\text { significado }\end{array}$ & $\begin{array}{c}\text { Significado } \\
\text { negativo }\end{array}$ \\
\hline Do seu time & $91,66 \%$ & $8,33 \%$ & 0 & 0 \\
\hline Do time rival & 0 & 0 & $66,66 \%$ & $33,33 \%$ \\
\hline
\end{tabular}

Fonte: Elaborado pelo autor, com base na pesquisa realizada.

Para o torcedor ouvir, ver, sentir, perceber cada coisa do seu time é fascinante, ele se sente envolvido com tudo que faz parte do seu clube. A marca do time de coração é para ele uma paixão, constituída dos mais puros sentimentos, isso porque ele possui interação direta com a mesma. As imagens de vivências, lembranças, conquistas, apoio, entre outras circunstâncias estão estabelecidas na mente do

\footnotetext{
${ }^{4}$ Termo utilizado para o ato de assistir a um jogo do time adversário torcendo contra o mesmo.
} 
torcedor através das experiências que lhe foram emitidas conforme sua convivência cultural e social com tal ambiente.

A partir das entrevistas realizadas percebeu-se também que a visualização de cada uma das cores separadas não possui o mesmo significado de quando combinadas com as demais cores constituintes da identidade do time. Dessa forma, mesmo que na maioria das entrevistas os gremistas tenham demonstrado maior identificação com o azul e os colorados com o vermelho, eles não associam as cores com os respectivos times sem a presença de outros elementos, fazendo referência a estes somente após a demonstração da combinação entre as cores ou quando integrados ao futebol.

A marca de um time de futebol, portanto, é formada por todos os elementos que envolvem o clube. Estes que aguçam os sentidos dos torcedores podem ser empregados em outras espécies de marcas, para isso, elas precisam desenvolver técnicas baseadas nos estímulos propostos por tal tipo de marca, capaz de provocar o seu público, no caso o torcedor.

$\mathrm{Na}$ questão referente ao time de futebol como marca emocional, todos os entrevistados, mesmo os não fanáticos, responderam positivamente que este é uma marca emocional. Os torcedores acreditam que o que sentem pelo seu time não tem comparação com outra marca qualquer, por exemplo. Apesar de outras marcas tentarem tomar algumas atitudes inovadoras não conseguem estimular seus públicos igualmente, elas deveriam investir em algo inesperado que seja percebido de forma inusitada. O torcedor sente uma emoção própria, principalmente, quando relacionada com momentos do time como os ocorridos durante um jogo, ele fica esperando sem saber de fato o que vai acontecer até o final da partida, portanto, está sempre pronto para vibrar, xingar, gritar, vaiar, comemorar e outras infinitas sensações que o envolve no momento específico.

Dessa forma, é possível perceber a importância da marca de um time de futebol para o torcedor. Para ele, tal marca se torna um vício que acaba por fazer parte da sua vida, ele sente pela marca do time algo inusitado, que não consegue expressar com palavras. A marca de um time se constitui na mente do torcedor de forma totalmente consolidada, independente se o time está em um momento ruim ou glorioso, o torcedor não deixa de estar junto com ele para demonstrar seu apoio, a relação entre eles é tão forte que nenhuma derrota pode abalar.

\section{CONCLUSÕES}

Conforme pôde ser visto durante o trabalho, a marca emocional é aquela capaz de interagir com seu público através das sensações que provoca emocionalmente. Ela consegue penetrar inconscientemente no imaginário, através dos estímulos sensoriais que provoca, criando uma relação de convívio com seu público, que se torna parte da sua construção e concretização. Nesse contexto, devem considerados os elementos constituintes de uma marca, como fazem as marcas de times de futebol, que priorizam seus diversos elementos, estes que as caracterizam e identificam dentro do contexto específico. Tais elementos vão desde cores e símbolos (escudos, bandeira, mascote, uniforme, hino, cantos, entre outros) até momentos e gestos realizados pelos clubes que de alguma maneira provocam emocionalmente o torcedor. A partir desses elementos, o time consegue capacitar sua marca de interagir diretamente com seu público, causando diferentes sensações a ele. 
O time de futebol é sem dúvida uma marca emocional capaz de instigar os sentimentos e instintos do torcedor, que fazem dele um fã da marca. Cada elemento constituinte transmite um sentido próprio ao torcedor, com o qual se identifica a partir das lembranças de momentos vividos relacionadas a este. Um artefato em particular do time, pode elucidar diferentes entendimentos e constatações de sua marca, atribuindo a ela qualidades que favorecem a sua consolidação na mente do torcedor.

Para o torcedor, a marca de seu time é como se fosse única, ela existe na sua vida como se fosse parte dele, devido a todos os estímulos provocados por ela enfatizados durante o trabalho. Outras marcas também podem ser capazes de alcançar uma relação de afeto mais próxima de seus públicos, para isso, devem seguir algumas características de marcas já incorporadas na mente dos mesmos.

Nesse caso, pode ser utilizado o processo de Benchmarking, em que é realizada uma busca pelas melhores técnicas desempenhadas por empresas ou marcas, que se destacam através de suas estratégias de comunicação. Devem ser feitas análises de marcas já existentes que apresentam características de qualificação e se sobressaiam dentre as outras, como as de futebol elucidadas no trabalho, isto, para que suas estratégias comunicacionais possam ser aplicadas as demais conforme necessário.

Algumas marcas até conseguem penetrar mais profundamente no imaginário do seu público e, em alguns casos, se consolidarem, se tornando um objeto de desejo, essas devem ainda criar estratégias para se manterem concretizadas na mente desse público e permanecerem à frente das concorrentes. Porém, isso acontece com poucas marcas. Como, por exemplo, a Coca-Cola e a Harley Davidson, que a partir de suas estratégias de desenvolvimento de marca conseguem mantê-las no topo da mente de certos públicos.

Nesse sentido, as marcas devem criar algum estímulo específico que a caracterize e que de alguma forma consiga interagir diretamente com o seu público, provocando-o emocionalmente através dos sentidos. Além disso, como características mais primordiais, estas marcas devem ter atributos de boa qualidade, como também, manter um relacionamento eficaz com tal público e estabelecer metas de divulgação de marca bem elaboradas.

Algumas técnicas que podem ser utilizadas pelas marcas de consumo são: a apropriação da cultura, a criação de cheiros específicos para um produto que o tornará distinto, como também, uma tecnologia avançada capaz de atrair o público, ou alguma textura especial que o envolva pelo toque, uma música que seja uma representação da marca com a qual ele se identifique, ou ainda podem ser promovidos eventos que irão estimular o consumidor e estabelecer uma relação de convívio mais próxima entre eles, dentre outros fatores que possam provocar sentido ao público específico.

Com base nesse estudo, percebe-se que existem diferentes estratégias de comunicação que podem ser aplicadas às marcas de consumo de modo que elas penetrem sensivelmente nos públicos. Para isso, deve-se ter como base estudos qualitativos que apresentem as características de marcas bem sucedidas, bem como, a análise do público específico para entender o que ele sente em relação a elas, do próprio contexto em que se encontram inseridas, dos fatores que interferem culturalmente na consolidação dessas marcas e demais elementos que possam ser relevantes para a compreensão da constituição delas como um todo. Tendo consciência de todas as características eficazes que cooperam para a solidificação de certas marcas, diversas outras podem ser levadas a alcançar o êxito, devendo estas se 
mobilizarem a partir de atitudes estratégicas que irão provocar emocionalmente 0 imaginário do seu público, sustentando uma ideia de consolidação de marca, como fazem as dos times de futebol.

\section{REFERÊNCIAS}

ANALISES DOM JOKER. Disponível em:

$<$ http://analisesdomjoker.blogspot.com/2009/06/analise-gremio-foot-ballporto.html>. Acesso em 26 de set. 2010, il. color.

AZEVEDO e SOUZA, Valdemarina Bidone de. Pesquisa Bibliográfica. Porto Alegre:1995.

BAUER, Martin e GASKELL, George. Pesquisa Qualitativa com texto, imagem e som: um manual prático. Petrópolis: Vozes, 2002.

BLOG ORGANIZADAS. Disponível em: $<$ http://blogorganizadas.wordpress.com/2009/12/12/barra-bravageral-do-gremiogdg/>. Acesso em 29 de set. 2010.

DAOLIO, Jocimar. Futebol, cultura e sociedade. 1a ed. São Paulo: Autores Associados, DURAND, Gilbert. O Imaginário: ensaio acerca das ciências e da filosofia das imagens. Rio de Janeiro: DIFEL, 1998.

EAGLEMAN, David. Incógnito: as vidas secretas do cérebro. Tradução de Ryta Vinagre. Rio de Janeiro: Rocco, 2012.

GRÊMIO 1983. Disponível em: <http://gremio1983.blogspot.com/search/label/mosqueteiro>. Acesso em: 04 de out. 2010, il. color.

GRÊMIO FOOT-BALL PORTO ALEGRENSE. Disponível em:

<http://www.gremio.net/home/>. Acesso em 13 de set. 2010.

GUIMARÃES, Luciano. A cor como informação: a construção biofísica, lingüística e cultural da simbologia das cores. 1a ed. São Paulo: Annablume, 2000.

LEDOUX, Joseph. 0 Cérebro Emocional: os misteriosos alicerces da vida emocional. Rio de Janeiro: Objetiva, 2001.

PENN, Gemma. Análise Semiótica de imagens paradas. In BAUER, Martin e GASKELL, George. Pesquisa Qualitativa com texto, imagem e som: um manual prático.

Petrópolis: Vozes, 2002, p. 319-342.

RAFAEL NEMITZ. Disponível em: <http://rafaelnemitz.blogspot.com/2009/04/o-nomeainda-nao-foi-revelado-mas-o.html>. Acesso em 26 de set. 2010, il. color.

SPORT CLUB INTERNACIONAL. Disponível em:

<http://www.internacional.com.br/home.php>. Acesso em 13 de set. 2010.

SEMPRE IMORTAL. Disponível em: <http://sempreimortal.wordpress.com/>. Acesso em:26 de set. 2010, il. color.

STOLTZ, Tania. Saúde Psicológica sob a perspectiva de Abraham Maslow. 1ạ ed. Campinas: Editora Alínea, 2000.

THOMPSON, John B. Ideologia e Cultura Moderna. 4ae ed. Petrópolis: Vozes, 1995. 